Published under the Auspices of the International Association for Suicide Prevention (IASP)

\section{Crisis \\ The Journal of Crisis Intervention and Suicide Prevention}

Your article has appeared in a journal published by Hogrefe Publishing. This eoffprint is provided exclusively for the personal use of the authors. It may not be posted on a personal or institutional website or to an institutional or disciplinary repository.

If you wish to post the article to your personal or institutional website or to archive it in an institutional or disciplinary repository, please use either a pre-print or a post-print of your manuscript in accordance with the publication release for your article and our "Online Rights for Journal Articles"

(www.hogrefe.com/journals). 


\title{
Hospital-Treated Deliberate Self-Harm in the Western Area of Northern Ireland
}

\author{
Paul Corcoran ${ }^{1,2}$, Eve Griffin ${ }^{1}$, Amanda O'Carroll $^{3}$, \\ Linda Cassidy ${ }^{3}$, and Brendan Bonner ${ }^{3}$ \\ ${ }^{1}$ National Suicide Research Foundation, University College Cork, Ireland \\ ${ }^{2}$ Departments of Epidemiology \& Public Health and of Obstetrics \& Gynaecology, \\ University College Cork, Ireland, ${ }^{3}$ Public Health Agency, Derry, Northern Ireland
}

\begin{abstract}
Background: The Northern Ireland Registry of Deliberate Self-Harm was established as an outcome of the Northern Ireland Suicide Prevention Strategy and Action Plan - Protect Life, beginning in the Western Health and Social Care Trust area. Aims: The study aimed to establish the incidence of hospital-treated deliberate self-harm in the Western Area of Northern Ireland, and to explore the profile of such presentations. Method: Deliberate self-harm presentations made to the three hospital emergency departments operating in the area during the period 2007-2012 were recorded. Results: There were 8,175 deliberate self-harm presentations by 4,733 individuals. Respectively, the total, male, and female age-standardized incidence rate was 342,320 , and 366 per 100,000 population. City council residents had a far higher self-harm rate. The peak rate for women was among $15-19$-year-olds $(837$ per 100,000) and for men was among 20-24-year-olds $(809$ per 100,000$)$. Risk of repetition was higher in 35-44-year-old patients if self-cutting was involved, but was most strongly associated with the number of previous selfharm presentations. Conclusion: The incidence of hospital-treated self-harm in Northern Ireland is far higher than in the Republic of Ireland and more comparable to that in England.
\end{abstract}

Keywords: self-harm, suicidal behavior, hospital emergency departments

Suicidal behavior is recognized as a significant public health issue in many countries. This has been particularly evident in the United Kingdom and in Ireland where several national strategies have been implemented during the past decade (Department of Health, 2002; Department of Health, Social Services and Public Safety [DHSSPS], 2006; Health Service Executive [HSE], 2005; Scottish Executive, 2002). In Northern Ireland, the Investing for Health Strategy (Department of Health, Social Services and Social Policy, 2002) identified the need to promote mental health and emotional well-being and to address the issue of suicide. The 30 actions contained in the Promoting Mental Health Strategy and Action Plan (DHSSPS, 2003) were designed to support mental and emotional well-being. Concern about an increase in the number of suicides, particularly among young people, led to the publication of the Northern Ireland Suicide Prevention Strategy and Action Plan in 2006 - Protect Life (DHSSPS, 2006). The document highlighted the extent of the problem, not only of suicide but also of deliberate self-harm that led to hospital admission. Some 35,996 hospital admissions (1.5\% of all admissions) were recorded as incidents of self-harm in the 5 years preceding the publication of the strategy and during these years the number of admissions due to self-harm increased by $9.2 \%$. The strategy recognized that there were no data in Northern Ireland regarding incidents of self-harm treated in hospital emergency departments (EDs) only and consequently specified that a self-harm registry be developed.

In 2007, the DHSSPS Northern Ireland commissioned the cross-border body "Co-operation and Working Together" (CAWT; http://www.cawt.com) to establish the Northern Ireland Registry of Deliberate Self-Harm, on a pilot basis, in the Western Health and Social Care Trust area and to do so by adapting the methods used by the National Suicide Research Foundation in the Republic of Ireland in their operation of the National Registry of Deliberate Self Harm (Perry et al., 2012). A multiagency steering group was assembled to direct the registry and to ensure adherence to the project plan. This paper reports on the findings of the Northern Ireland Self Harm Registry in the Western Trust for the period 2007-2012. It reports on the incidence of persons presenting to hospital EDs as a result of selfharm by sex, age, and area, the nature of the self-harming behavior involved in the acts, and patterns related to the timing of the presentations to hospital. 


\section{Method}

\section{Setting}

There are five health and social care trusts in Northern Ireland and the area of the Western Trust defined the study catchment area. It has a population of almost 300,000 (296,610 in 2012) thereby accounting for $16.3 \%$ of the population of Northern Ireland (1,823,634 in 2012). The Western Area is made up of the predominantly urban area of Derry City Council (population $=108,586$ in 2012) and four less densely populated district council areas: Fermanagh (62,400 in 2012), Limavady (33,761 in 2012), Omagh ( 51,830 in 2012), and Strabane (40,033 in 2012). In 2007 the Western Area was serviced by three hospital accident EDs: Altnagelvin Hospital (Londonderry), Erne Hospital (Enniskillen), and Tyrone County Hospital (Omagh). The latter was downgraded from an ED to an urgent care department in March 2009, after which the number of selfharm presentations was greatly reduced and registry data collection ceased. This study includes data on self-harm presentations to Tyrone County Hospital for the period 2007-2010 and to Altnagelvin Hospital and Erne Hospital for 2007-2012.

\section{Definition of Deliberate Self-Harm}

The following definition was adopted by the registry: "An act with non-fatal outcome in which an individual deliberately initiates a non-habitual behaviour, that without intervention from others will cause self-harm, or deliberately ingests a substance in excess of the prescribed or generally recognised therapeutic dosage, and which is aimed at realising changes that the person desires via the actual or expected physical consequences" (Schmidtke, BilleBrahe, De Leo, \& Kerkhof, 2004, p. 12-13). This is an internationally recognized definition that was derived for the WHO/Euro Multicentre Study on Suicidal Behaviour (formerly known as the WHO/Euro Multicentre Study on Parasuicide). The definition is used by the RoI National Registry of Deliberate Self Harm (Perry et al., 2012) and is broadly consistent with the definition used in the UK Multicentre Study (Hawton et al., 2007).

\section{Case Finding}

All data were collected by trained data registration officers. In the Tyrone County Hospital Urgent Care Department, all records of attendances to the department were checked manually by a data registration officer. In the ED of the Altnagelvin and Erne hospitals, a two-stage process was developed whereby a keyword search was first undertaken of the free-text field in the Symphony hospital IT system, which records the reason for the patients' presentation as completed by the triage nurse. All presentations flagged as potential cases by the keyword search were then examined by the data registration officer. The reliability of the key- word search approach was established at the start of the study through a quality control exercise. All presentations for a specified period were manually examined and cases of deliberate self-harm identified. The keyword search was performed on the same presentations and the flagged potential cases were examined to establish whether all deliberate self-harm cases were included. The list of keywords was extended to ensure inclusion of all deliberate self-harm cases and this revised list was used for the study period. Further audits and checks of the performance of the keyword search were carried out to ensure the completeness of the case finding procedures.

\section{Data Analysis}

The annual incidence rate per 100,000 population was calculated for the total, male, and female population (and for age-sex subgroups) based on the number of persons (rather than events) resident in the catchment area who presented to hospital following deliberate self-harm in each calendar year. Where appropriate, direct standardization was carried out using the European Standard Population. The rate for the geographically defined areas of Derry City Council and Fermanagh, Limavady, Omagh, and Strabane District Council areas was calculated based on the number of persons resident in the area who presented with deliberate self-harm irrespective of whether they were treated in that area or elsewhere. Northern Ireland Statistics and Research Agency mid-year population estimates were obtained for each study year at all required levels of disaggregation. Exact Poisson 95\% confidence intervals were calculated for the rates using StatsDirect version 2.7.7. These intervals are displayed by error bars in relevant charts.

Analysis of repetition used a 1-year follow-up period, that is, a self-harm patient repeated if she/he re-presented to one of the three hospital EDs due to self-harm in the 365 days following an index presentation. Data were not available on patients' history of hospital-treated deliberate selfharm prior to the study period. The data on patients' history of self-harm not resulting in hospital treatment were also not available. As it is well-recognized as the strongest risk factor for repetition, the following steps were taken in order to incorporate some measure of previous history of self-harm into our analysis of risk of repetition. The analysis was confined to deliberate self-harm patients treated from 2008 to 2011. This allowed patients the 1-year follow-up period required for the repetition outcome but also a period of 12 months preceding their index self-harm presentation during 2008-2011. The number of self-harm presentations to hospital in these 365 days was used as a measure of the previous history of self-harm. Variation in the rate of repetition was examined by the following variables: sex, age group, city residence, day and time of self-harm presentation, method of self-harm, involvement of alcohol in the act, and previous history of self-harm. A series of univariate logistic regression models were used to estimate the crude association between these variables and repetition. A multivariate logistic regression model in which all the variables were included was then used to esti- 
Table 1. Incidence of hospital-treated deliberate self-harm in Northern Ireland Western Area, 2007-2012

\begin{tabular}{|c|c|c|c|c|c|c|c|c|c|}
\hline & \multicolumn{3}{|c|}{ Persons } & \multicolumn{3}{|c|}{ Male } & \multicolumn{3}{|c|}{ Female } \\
\hline & Rate $^{\mathrm{a}}$ & $(95 \% \mathrm{CI})$ & $\%$ Difference & Rate $^{\mathrm{a}}$ & $(95 \% \mathrm{CI})$ & $\%$ Difference & Rate $^{a}$ & $(95 \% \mathrm{CI})$ & $\%$ Difference \\
\hline Western Area & 342 & $(334-351)$ & - & 320 & $(308-331)$ & - & 366 & (354-379) & - \\
\hline Derry City & 470 & $(453-486)$ & $+39.1 \%$ & 461 & $(438-485)$ & $+49.7 \%$ & 479 & $(456-502)$ & $+29.5 \%$ \\
\hline Fermanagh District & 274 & $(257-291)$ & $-18.9 \%$ & 268 & $(244-292)$ & $-13.0 \%$ & 282 & $(257-307)$ & $-23.8 \%$ \\
\hline Limavady District & 227 & $(207-248)$ & $-32.8 \%$ & 189 & $(163-216)$ & $-38.6 \%$ & 269 & $(236-302)$ & $-27.3 \%$ \\
\hline Omagh District & 252 & $(234-270)$ & $-25.4 \%$ & 212 & (189-236) & $-31.2 \%$ & 293 & $(266-321)$ & $-20.8 \%$ \\
\hline Strabane District & 304 & $(281-326)$ & $-10.1 \%$ & 265 & $(236-295)$ & $-14.0 \%$ & 343 & $(310-377)$ & $-7.3 \%$ \\
\hline
\end{tabular}

Note. ${ }^{a}$ Average annual person-based age-standardized rate per 100,000 (all ages). Difference is the percentage difference from the incidence rate for the Western Area.
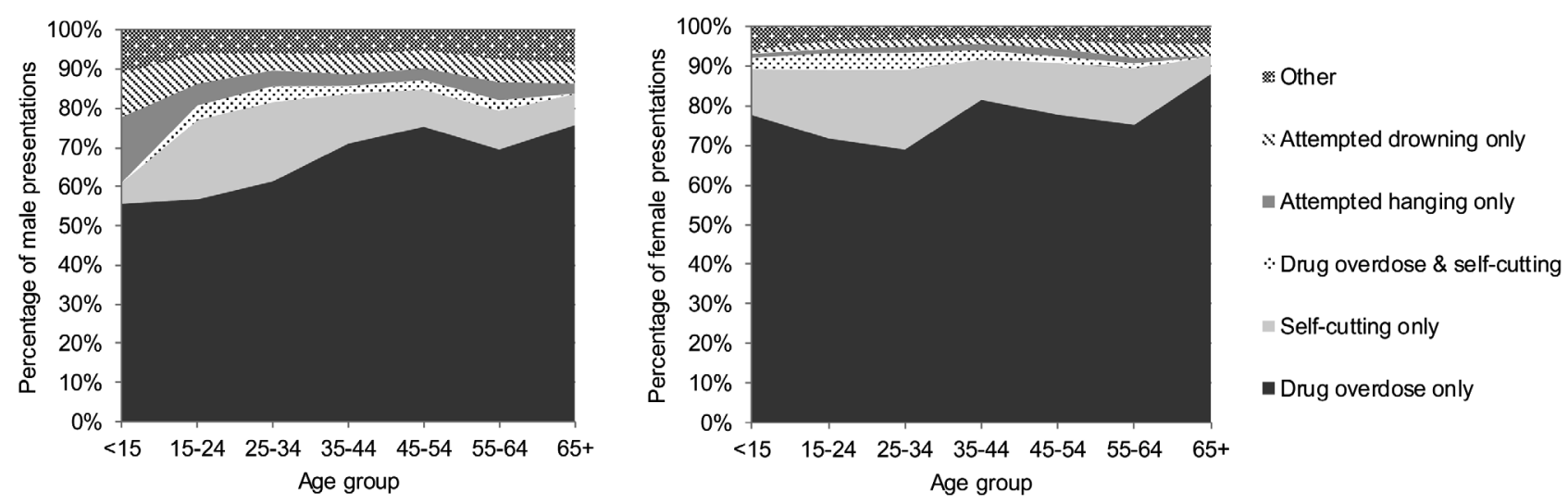

Figure 1. Method of deliberate self-harm involved in male (left chart) and female (right chart) presentations to hospital in the Northern Ireland Western Area, 2007-2012.

mate their independent association with risk of repetition. Odds ratios, their corresponding 95\% confidence intervals, and an indication of their level of statistical significance ( $p$ value) were reported as measures of association. The standard 5\% level of statistical significance was adopted, that is, $p<.05$.

\section{Results}

\section{Incidence of Deliberate Self-Harm}

During 2007-2012, there were 8,175 deliberate self-harm presentations to hospital involving 4,733 individuals. Residents of the catchment area accounted for 8,024 (98.2\%) of the presentations and 4,618 $(97.6 \%)$ of the individuals. Female residents accounted for $53.6 \%(n=4,298)$ of these presentations and $53.7 \%(n=2,479)$ of the individual patients.

The incidence of hospital-treated deliberate self-harm by Western Area residents in each year of the study is detailed in the table in Electronic Supplementary Material 1. The female rate was significantly higher than the male rate, $15 \%$ when all ages were considered and $12 \%$ higher considering those aged 15 years and older. Deliberate selfharm rates were far higher among city council residents than among residents of the district councils, particularly for men. Male city council residents had a self-harm rate almost $50 \%$ higher than in the Western Area as a whole (461 vs. 320 per 100,000; Table 1).

There was a striking pattern in the age-sex-specific incidence of hospital-treated deliberate self-harm (see figure in Electronic Supplementary Material 2). The peak rate was among 15-19-year-old female subjects $(837,95 \%$ CI =768-910, per 100,000) and 20-24-year-old male subjects $(809,95 \%$ CI $=739-883$, per 100,000). For both genders the incidence rate decreased with increasing age, although there was evidence of a secondary peak among women aged 35-49 years. In most age groups male and female self-harm rates were similar. However, the female self-harm rate was far higher in 10-19-year-olds (499.7 vs. 263.4 per 100,000) and was also higher in those aged $40-44$ (581.2 vs. 465.2 per 100,000$)$ and $50-54$ years $(404.0$ vs. 276.9 per 100,000).

\section{Methods of Self-Harm}

Almost three quarters $(70.4 \%)$ of the presentations involved drug overdose as the sole method of self-harm. Method of self-harm varied by gender $\left(\chi^{2}=184.35, d f=5\right.$, $p<.001)$. In particular, drug overdose was more common among women and this was evident across all ages 

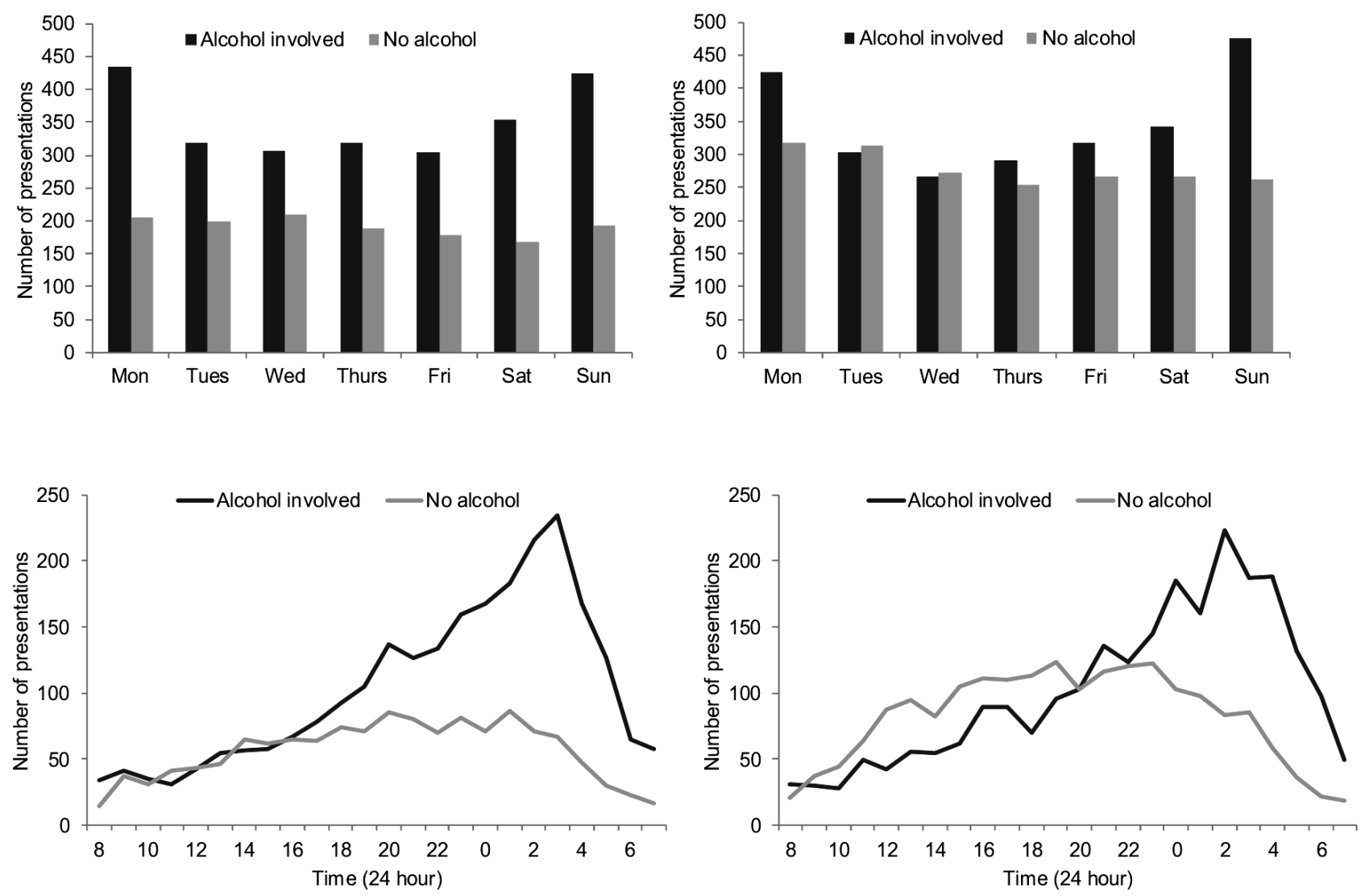

Figure 2. Frequency of male (left-hand charts) and female (right-hand charts) deliberate self-harm presentations to hospital by day of the week and hour of the day with and without the involvement of alcohol.

(Figure 1). Among men this method of self-harm became more prevalent with increasing age. Self-cutting was the only other common method, used as the sole method in $16.0 \%$ and $15.1 \%$ of male and female presentations, respectively. While relatively rare, male self-harm presentations more often involved the more lethal methods of attempted hanging ( $4.1 \%$ vs. $1.4 \%)$ and attempted drowning (5.6\% vs. $2.1 \%$ ). Alcohol was involved in $59.7 \%$ of deliberate self-harm presentations, more often in self-harm by men $\left(64.8 \%\right.$ vs. $\left.55.4 \% ; \chi^{2}=74.60, d f=1, p<.001\right)$. Alcohol was most prevalent in acts by 35-54-year-old men $(69.4 \%)$ and women $(63.3 \%)$.

\section{Timing of Presentation to Hospital}

The frequency of self-harm presentations to hospital varied according to day of the week, with an excess of presentations to hospital on Mondays and Sundays. This excess was evident for men and women and was due to acts where the individual had consumed alcohol (Figure 2). Alcohol was also associated with the pattern of self-harm presentations made to hospital over the course of the day (Figure 2). Self-harm presentations were least frequent in the hours before noon, whether alcohol was involved or not. There was an increase in presentations over the course of the afternoon. The evening saw a continued increase in alcohol-related self-harm presentations for men and women until a peak in the early hours of the morning. By contrast, the frequency of self-harm presentations that did not involve alcohol did not increase over the course of the evening and night.

\section{Repetition}

Three quarters $(73.0 \%, n=3,455)$ of the 4,733 self-harm patients made only one presentation during the 6-year study period. Fifty-eight patients made at least ten selfharm presentations during this time. These 58 patients accounted for just $1.2 \%$ of all patients, but they made a total of 1,032 presentations thereby accounting for one eighth of all self-harm acts treated in hospital $(n=1,032,12.6 \%)$.

Considering the period 2007-2011, which allows for a 1-year follow up, there were 6,706 self-harm presentations by 4,041 patients. The rate of repetition within 1 year was $33.8 \%$ based on presentations $(2,266$ of 6,706$)$ and $18.0 \%$ based on patients (726 of 4,041). There was some indication that the rate of repetition varied during this period $\left(\chi^{2}=15.9(4), p=.005\right)$. The 1 -year repetition rate was $34.0 \%$ following presentations in 2007 ; it fell to $30.5 \%$ following presentations in 2008 but increased to $32.8 \%$, 
Table 2. Factors associated with risk of repetition within 1 year for the 3,337 deliberate self-harm (DSH) patients treated during 2008-2011

\begin{tabular}{|c|c|c|c|c|c|c|c|}
\hline Variable & Category & Repeated ( $n$ ) & $\%$ & Crude $O R$ & $(95 \% \mathrm{CI})$ & Adjusted $O R$ & $(95 \% \mathrm{CI})$ \\
\hline \multirow[t]{2}{*}{ Sex } & Male & 303 & $19.6 \%$ & 1.00 & (Ref) & 1.00 & (Ref) \\
\hline & Female & 308 & $17.2 \%$ & 0.85 & $(0.71-1.01)$ & 0.92 & $(0.76-1.11)$ \\
\hline \multirow[t]{5}{*}{ Age } & $<25$ years & 193 & $16.8 \%$ & 1.00 & (Ref) & 1.00 & (Ref) \\
\hline & $25-34$ years & 146 & $19.8 \%$ & 1.23 & $(0.97-1.55)$ & 1.21 & $(0.94-1.54)$ \\
\hline & $35-44$ years & 152 & $20.5 \%$ & $1.28 *$ & $(1.01-1.62)$ & $1.30^{*}$ & $(1.02-1.67)$ \\
\hline & $45-54$ years & 88 & $17.3 \%$ & 1.04 & $(0.79-1.37)$ & 1.04 & $(0.78-1.39)$ \\
\hline & 55 years + & 32 & $15.8 \%$ & 0.93 & $(0.62-1.40)$ & 0.97 & $(0.64-1.49)$ \\
\hline \multirow[t]{2}{*}{ City resident } & No & 272 & $16.3 \%$ & 1.00 & (Ref) & 1.00 & (Ref) \\
\hline & Yes & 339 & $20.3 \%$ & $1.31 * *$ & $(1.10-1.56)$ & $1.25^{*}$ & $(1.04-1.50)$ \\
\hline \multirow[t]{2}{*}{ Weekend } & No & 427 & $18.3 \%$ & 1.00 & (Ref) & 1.00 & (Ref) \\
\hline & Yes & 184 & $18.3 \%$ & 1.00 & $(0.83-1.22)$ & 0.97 & $(0.80-1.19)$ \\
\hline \multirow[t]{6}{*}{ Time } & 8 a.m. $<$ noon & 38 & $14.7 \%$ & 1.00 & (Ref) & 1.00 & (Ref) \\
\hline & Noon < 4 p.m. & 73 & $16.2 \%$ & 1.12 & $(0.73-1.71)$ & 1.21 & $(0.78-1.88)$ \\
\hline & 4 p.m. $<8$ p.m. & 112 & $18.9 \%$ & 1.35 & $(0.90-2.01)$ & 1.43 & $(0.95-2.17)$ \\
\hline & 8 p.m. $<$ midnight & 141 & $19.6 \%$ & 1.41 & $(0.95-2.08)$ & 1.42 & $(0.95-2.13)$ \\
\hline & Midnight $<4$ a.m. & 167 & $18.8 \%$ & 1.34 & $(0.91-1.96)$ & 1.24 & $(0.83-1.84)$ \\
\hline & 4 a.m. $<8$ a.m. & 80 & $18.9 \%$ & 1.35 & $(0.89-2.06)$ & 1.27 & $(0.82-1.97)$ \\
\hline \multirow[t]{6}{*}{ Method } & Drug OD only & 411 & $16.2 \%$ & 1.00 & (Ref) & 1.00 & (Ref) \\
\hline & Self-cutting only & 111 & $29.3 \%$ & $2.14 * * *$ & $(1.67-2.73)$ & $2.11^{* * *}$ & $(1.64-2.73)$ \\
\hline & OD and self-cutting & 24 & $37.5 \%$ & $3.10 * * *$ & $(1.85-5.20)$ & $3.08 * * *$ & $(1.81-5.25)$ \\
\hline & Attempted hanging & 12 & $12.9 \%$ & 0.77 & $(0.41-1.42)$ & 0.76 & $(0.41-1.42)$ \\
\hline & Attempted drowning & 29 & $21.8 \%$ & 1.44 & $(0.94-2.20)$ & 1.32 & $(0.85-2.07)$ \\
\hline & Other & 24 & $17.8 \%$ & 1.12 & $(0.71-1.76)$ & 1.19 & $(0.75-1.88)$ \\
\hline \multirow[t]{2}{*}{ Alcohol } & No & 232 & $16.5 \%$ & 1.00 & (Ref) & 1.00 & (Ref) \\
\hline & Yes & 379 & $19.6 \%$ & $1.23 *$ & $(1.03-1.47)$ & 1.09 & $(0.90-1.33)$ \\
\hline \multirow[t]{4}{*}{ DSH in previous year } & None & 550 & $17.2 \%$ & 1.00 & (Ref) & 1.00 & (Ref) \\
\hline & One & 28 & $32.6 \%$ & $2.33 * * *$ & $(1.47-3.69)$ & $2.11 * *$ & $(1.32-3.40)$ \\
\hline & Two & 11 & $50.0 \%$ & $4.83 * * *$ & $(2.08-11.19)$ & $4.80 * * *$ & $(2.04-11.29)$ \\
\hline & Three or more & 22 & $91.7 \%$ & $53.10 * * *$ & $(12.45-226.47)$ & $49.63^{* * *}$ & (11.53-213.68) \\
\hline
\end{tabular}

$* p<.05 . * * p<.01 . * * * p<.001$

$34.2 \%$, and $37.4 \%$ following presentations in 2009,2010 , and 2011 , respectively.

There were 3,337 deliberate self-harm patients treated during 2008-2011, of whom $611(18.3 \%)$ made a repeat presentation within 12 months. Table 2 details the rate of repetition across a range of factors. Male and female patients had a similar rate of repetition. The multivariate analysis showed an increased risk of repetition associated with patients aged 35-44 years (20.5\%; adjusted $O R=1.30, p<$ $.05)$, patients who were city residents (20.3\%; adjusted $O R$ $=1.25, p<.05)$, and patients who engaged in self-cutting only $(29.3 \%$; adjusted $O R=2.11, p<.001)$ or in combination with drug overdose (37.5\%; adjusted $O R=3.08$, $p<.001)$. However, by far the strongest association with risk of repetition was recent history of hospital-treated deliberate self-harm. The repetition rate of patients who had not presented to hospital in the previous year was $17.2 \%$. The repetition rate was twice as high for patients with one presentation in the past year $(32.6 \%$; adjusted $O R=2.11$, $p<.01)$. While acknowledging the small numbers involved, half of the patients with two recent self-harm presentations repeated within 1 year $(50.0 \%$; adjusted $O R=$ $4.80, p<.001)$, and this was the case for almost all $(91.7 \%$; adjusted $O R=49.63, p<.001$ ) of those with three or more recent presentations. 


\section{Discussion}

\section{Main Findings}

This is the first study to report on the incidence, pattern, and repetition of hospital-treated deliberate self-harm in Northern Ireland. The total, male, and female deliberate self-harm rate during 2007-2012 was 342, 320, and 366 per 100,000, respectively. Derry City council residents had a far higher self-harm rate, 50\% higher for men and 30\% higher for women. The peak rate for women was among 15-19-year-olds (837 per 100,000) and for men was among 20-24-year-olds (809 per 100,000). Drug overdose was involved as a method in approximately three quarters of self-harm presentations. Self-cutting was the only other common method. Self-harm presentations were more common on Sundays and Mondays and increased over the course of the day with a peak in the early hours of the morning. These temporal variations were strongly associated with the involvement of alcohol. Patients' risk of repetition was greatly influenced by the number of self-harm presentations made in the previous year.

The incidence of hospital-treated deliberate self-harm is generally higher in the UK and Ireland than in other European countries (Arensman et al., 2008; Hawton et al., 2007; Jimenez-Trevino et al., 2012; Perry et al., 2012; Schmidtke et al., 2004). Most studies in this area have been based on urban catchment populations, but it has been shown that urban populations have far higher rates of hospital-treated deliberate self-harm than rural populations (Corcoran, Arensman, \& Perry, 2007; Harriss \& Hawton, 2011). Consistently, higher rates have been observed among the young and among women, although this gender difference is less pronounced in the UK and Ireland than in other European countries (Hawton et al., 2007; Jimenez-Trevino et al., 2012; Perry et al., 2012; Schmidtke et al., 2004). Drug overdose is the prominent method in cases of hospital-treated deliberate self-harm and a wide variation of drugs are involved (Griffin et al., 2014), followed by self-cutting, and the frequent involvement of alcohol (Michel et al., 2000). It has been shown that a higher number of presentations occur on Sundays and Mondays and that numbers increase over the course of the day and peak around midnight and the early hours of the morning (Griffin, Arensman, Wall, Corcoran, \& Perry, 2013; Gunnell, Bennewith, Peters, House, \& Hawton, 2005; Hawton et al., 2007).

A systematic review estimated that approximately $15 \%$ of self-harm patients repeat within 1 year (Owens, Horrocks, \& House, 2002). More recent UK studies have reported 1-year, person-based repetition rates of 14-23\% (Bergen, Hawton, Waters, Cooper, \& Kapur, 2010; Kapur et al., 2006; Lilley et al., 2008). One-year repetition rates reported from analysis of all presentations are higher $33 \%$ and $30 \%$ in UK and Irish studies, respectively (Lilley et al., 2008; Perry et al., 2012). Self-harm involving cutting has consistently been associated with increased risk of repetition but the strongest risk factor for repetition is previous history of self-harm, in particular the number of re- cent presentations (Bergen et al., 2010; Corcoran, Keeley, O’Sullivan, \& Perry, 2004; Lilley et al., 2008; Perry et al., 2012).

This study indicates that the incidence of hospital-treated deliberate self-harm in Northern Ireland is about $70 \%$ higher than in the Republic of Ireland (342 vs. 198 per 100,000; Perry et al., 2012). The study confirms the ruralurban differential in self-harm with far higher rates among city residents. However, the Derry City rate is higher than the rate for Republic of Ireland cities (Corcoran et al., 2007). Compared to the cities in the Multicentre Study of Self-Harm in England, the incidence of self-harm in Derry is higher than in Oxford and Leeds, similar to Derby and lower than Manchester (Bergen et al., 2010; Hawton et al., 2007). These findings raise the question as to why the incidence of self-harm in Northern Ireland is far higher than in the neighboring Republic of Ireland and more comparable to that in England. Hospital emergency care is free in the UK whereas the majority must pay in the Republic of Ireland. Thus, it may be that the incidence of self-harm in the population is similar but that a higher proportion present to hospital in the UK than in the Republic of Ireland. Similarly, the higher self-harm rates in urban populations could be due to a higher proportion of urban residents who self-harm presenting to hospital, whereas persons who self-harm in rural areas may be more likely to go untreated or present to primary care. These issues warrant further investigation as they have important implications for service provision and the prevention of suicidal behavior. Further research is also required to explain why hospital-treated self-harm in the UK and Ireland is so much more common than in other European countries.

This study highlights the strong influence played by alcohol in the timing of self-harm presentations to the ED which has implications regarding the deployment of mental health professional to assess self-harm patients. These staff should ideally be on site when self-harm presentations are most frequent, but this is also when the greatest proportion of the patients are intoxicated with alcohol and therefore unsuitable for assessment. Studies have examined factors influencing the rate of self-harm patient assessment (Barr, Leitner, \& Thomas, 2004; Bennewith, Peters, Hawton, House, \& Gunnell; Gunnell et al., 2005) and clinical guidelines are available regarding assessment and management of the patients (Cassidy, Arensman, Keeley, \& Reidy, 2012; NICE, 2004) but the optimal deployment of mental health professionals to assess, refer, and follow-up with self-harm patients is not known. The study findings confirm the greatly increased risk of repetition for patients with a number of recent self-harm presentations and highlight the fact that a very small number of self-harm patients account a significant proportion of all presentations. Among patients with numerous self-harm presentations there is a high prevalence of personality disorders (Beghi \& Rosenbaum, 2010) and there is evidence that dialectical behavioral therapy is an effective treatment for this patient group (Mann et al., 2005). Such intensive therapy is required to meet the significant needs of these patients, and may be cost-effective given the burden of their presentations on the health services. 


\section{Strengths and Limitations}

This study has the strength of being based in a geographically defined catchment area with a balance of urban and rural population similar to that for the whole of Northern Ireland. It utilizes a registry methodology similar to that used in other settings (Bergen et al., 2010; Perry et al., 2012), thereby facilitating comparison of findings. The sample size was sufficient to provide relatively precise estimates of the incidence rate of hospital-treated deliberate self-harm by age, gender, year, and area, and to detect medium effects on risk of repetition as being statistically significant.

The study period was too short to discern the presence of trends in the rate of deliberate self-harm, but this will be done in subsequent work. The registry records a limited number of data items related to the extent, the nature, and the timing of self-harm. Other information related to the assessment, treatment, and referral of the patient warrants inclusion. Similarly there is a need to establish more longterm outcomes such as subsequent mortality by suicide and other causes.

\section{Conclusion}

This study has provided the first estimates of the incidence of hospital-treated deliberate self-harm in Northern Ireland. The registry is being implemented in all five Health Trusts and this will establish the extent of the problem for the whole of Northern Ireland. The figures now available may be used as the baseline in the assessment of the effect of further community health and health service initiatives aimed at reducing suicidal behavior.

\section{Acknowledgments}

We would like to acknowledge the members of the Northern Ireland Registry of Deliberate Self-Harm regional and local steering groups, the Northern Ireland Department of Health and Social Care, Northern Ireland Public Health Agency, Co-operation and Working Together, and the National Suicide Research Foundation Ireland, who have contributed to the development of the registry. Special thanks are also due to the data registration officers who collected the data and to staff of the various hospitals who facilitated the work.

The Northern Ireland Registry of Deliberate Self-Harm is funded by the Department of Health, Social Services and Public Safety, Northern Ireland through the Public Health Agency.

The authors have no conflict of interest to declare.

\section{Electronic Supplementary Material}

The electronic supplementary material is available with the online version of the article at http://dx.doi. org/10.1027/0227-5910/a000301

ESM1. Table.

Annual incidence of hospital-treated deliberate self-harm by residents of the Northern Ireland Western area in 20072012.

ESM2. Figure.

Annual age-sex-specific incidence of hospital-treated deliberate self-harm in the Northern Ireland Western area, 2007-2012.

\section{References}

Arensman, E., Fitzgerald, A. P., Bjerke, T., Cooper, J., Corcoran, P., Grad, O., ... Van Herringen, K. (2008). Deliberate selfharm and suicide: Gender-specific trend in eight European regions - preliminary findings. Abstract. Journal of Epidemiology and Public Health, 62(Suppl. 1).

Barr, W., Leitner, M., \& Thomas, J. (2004). Short shrift for the sane? The hospital management of self-harm patients with and without mental illness. Journal of Psychiatric and Mental Health Nursing, 11(4), 401-406.

Beghi, M., \& Rosenbaum, J. F. (2010). Risk factors for fatal and nonfatal repetition of suicide attempt: A critical appraisal. Current Opinion in Psychiatry, 23(4), 349-355.

Bennewith, O., Peters, T. J., Hawton, K., House, A., \& Gunnell, D. (2005). Factors associated with the non-assessment of self-harm patients attending an Accident and Emergency Department: Results of a national study. Journal of Affective Disorders, 89(1-3), 91-97.

Bergen, H., Hawton, K., Waters, K., Cooper, J., \& Kapur, N. (2010). Epidemiology and trends in non-fatal self-harm in three centres in England: 2000-2007. The British Journal of Psychiatry, 197(6), 493-498.

Cassidy, E., Arensman, E., Keeley, H. S., \& Reidy, J. (2012). Saving lives and reducing harmful outcomes: Care systems for self-harm and suicidal behaviour. National guidelines for the assessment and management of patients presenting to Irish emergency departments following self-harm. Cork, Ireland: National Suicide Research Foundation.

Corcoran, P., Arensman, E., \& Perry, I. J. (2007). The area-level association between hospital-treated deliberate self-harm, deprivation and social fragmentation in Ireland. Journal of Epidemiology and Community Health, 61(12), 1050-1055.

Corcoran, P., Keeley, H. S., O’Sullivan, M., \& Perry, I. J. (2004). The incidence and repetition of attempted suicide in Ireland. The European Journal of Public Health, 14(1), 19-23.

Department of Health. (2002). National suicide prevention strategy for England. London, UK: Author.

Department of Health, Social Services and Public Safety. (2003). Promoting mental health: Strategy and action plan, 20032008. Belfast, UK: DHSSPS.

Department of Health, Social Services and Public Safety. (2006). Protect life - A shared vision: The Northern Ireland suicide prevention strategy and action plan, 2006-2011. Belfast, UK: DHSSPS.

Department of Health, Social Services and Social Policy. (2002). Investing for health. Belfast, UK: DHSSPS. 
Griffin, E., Corcoran, P., O’Carroll, A., Cassidy, L., Perry, I. J., \& Bonner, B. (2014). Characteristics of hospital-treated intentional drug overdose in Ireland and Northern Ireland. $B M J$ Open, 4, e005557.

Griffin, E., Arensman, E., Wall, A., Corcoran, P., \& Perry, I. J. (2013). National Registry of Deliberate Self Harm annual report 2012. Cork, Ireland: National Suicide Research Foundation.

Gunnell, D., Bennewith, O., Peters, T. J., House, A., \& Hawton, K. (2005). The epidemiology and management of self-harm amongst adults in England. Journal of Public Health, 27(1), $67-73$.

Harriss, L., \& Hawton, K. (2011). Deliberate self-harm in rural and urban regions: A comparative study of prevalence and patient characteristics. Social Science \& Medicine, 73(2), 274-281.

Hawton, K., Bergen, H., Casey, D., Simkin, S., Palmer, B., Cooper, J., ... Owens, D. (2007). Self-harm in England: A tale of three cities. Multicentre study of self-harm. Social Psychiatry and Psychiatric Epidemiology, 42, 513-521.

Health Service Executive. (2005). Reach out - Irish national strategy for action on suicide prevention 2005-2014. Dublin, Ireland: HSE.

Jimenez-Trevino, L., Saiz, P. A., Corcoran, P., Garcia-Portilla, M. P., Buron, P., Garrido, M., ... Bobes, J. (2012). The incidence of hospital-treated attempted suicide in Oviedo, Spain. Crisis, 33(1), 46-53.

Kapur, N., Cooper, J., King-Hele, S., Webb, R., Lawlor, M., Rodway, C., \& Appleby, L. (2006). The repetition of suicidal behavior: A multicenter cohort study. Journal of Clinical Psychiatry, 67(10), 1599-1609.

Lilley, R., Owens, D., Horrocks, J., House, A., Noble, R., Bergen, H., ... Kapur, N. (2008). Hospital care and repetition following self-harm: Multicentre comparison of self-poisoning and self-injury. The British Journal of Psychiatry, 192(6), 440-445.

Mann, J. J., Apter, A., Bertolote, J., Beautrais, A., Currier, D., Haas, A., ... Hendin, H. (2005). Suicide prevention strategies: A systematic review. JAMA, 294(16), 2064-2074.

Michel, K., Ballinari, P., Bille-Brahe, U., Bjerke, T., Crepet, P., De Leo, D., ... Wasserman, D. (2000). Methods used for parasuicide: Results of the WHO/EURO Multicentre Study on Parasuicide. Social Psychiatry and Psychiatric Epidemiology, 35(4), 156-163.

NICE. (2004). Self-harm: The short-term physical and psychological management and secondary prevention of self-harm in primary and secondary care. Retrieved from http://www. nice.org.uk/guidance/cg 16

Owens, D., Horrocks, J., \& House, A. (2002). Fatal and non-fatal repetition of self-harm: Systematic review. The British Journal of Psychiatry, 181(3), 193-199.

Perry, I. J., Corcoran, P., Fitzgerald, A. P., Keeley, H. S., Reulbach, U., \& Arensman, E. (2012). The incidence and repetition of hospital-treated deliberate self harm: findings from the world's first national registry. PLoS ONE, 7(2), e31663.

Platt, S., Bille-Brahe, U., Kerkhof, A., Schmidtke, A., Bjerke, T., Crepet, P., ... Faria Sampaio, J. (1992). Parasuicide in Europe: The WHO/EURO multicentre study on parasuicide. I. Introduction and preliminary analysis for 1989. Acta Psychiatrica Scandinavica, 85(2), 97-104.

Schmidtke, A., Bille-Brahe, U., De Leo, D., \& Kerkhof, A. (2004). Suicidal behaviour in Europe: Results from the WHO/Euro Multicentre Study on Suicidal Behaviour. Göttingen, Germany: Hogrefe \& Huber.
Scottish Executive. (2002). Choose life: A national strategy and action plan to prevent suicide in Scotland. Edinburgh, UK: Author.

Stats Direct. (2012). Stats Direct (version 2.7.7) [Statistical software]. Available at www.statsdirect.com

Received February 12, 2014

Revision received September 26, 2014

Accepted September 28, 2014

Published online January 12, 2015

About the authors

Dr. Paul Corcoran is Senior Lecturer with the Departments of Epidemiology \& Public Health and of Obstetrics \& Gynaecology in University College Cork, Ireland, and has worked with the National Suicide Research Foundation since 1994. His primary research interest is the epidemiology of suicidal behavior and related health information systems, in particular monitoring systems for hospital-treated deliberate self-harm.

Dr. Eve Griffin is a postdoctoral researcher with the National Suicide Research Foundation (Cork, Ireland) and has a $\mathrm{PhD}$ in $\mathrm{Ap}$ plied Psychology from University College Cork. She is the manager of the National Registry of Deliberate Self-Harm, a system which collects data on all Irish hospital emergency department presentations involving self-harm.

Amanda O'Carroll is Senior Health Improvement Officer within the Public Health Agency of Northern Ireland. In 2007 Amanda led the project that introduced the Self-Harm Registry into Northern Ireland and was involved in the roll out of the registry across Northern Ireland. Amanda holds a postgraduate certificate in Health Informatics.

Linda Cassidy is a Health and Social Wellbeing Improvement Officer within the Public Health Agency of Northern Ireland and is project manager of the Northern Ireland Registry of Deliberate Self-harm. The Northern Ireland Registry collects data on presentations to 12 hospital emergency departments across Northern Ireland as a result of deliberate self-harm.

Brendan Bonner is Head of Health and Social Wellbeing Improvement in the Public Health Agency of Northern Ireland. He specifically leads on the regional commissioning of services related to suicide prevention, self-harm, and crisis support. Brendan has been involved in the Deliberate Self-Harm project since the initial pilot in 2007.

\section{Paul Corcoran}

National Suicide Research Foundation

4.28 Western Gateway Building

University College Cork

Cork

Ireland

Tel. +353 21 420-5043

E-mail pcorcoran@ucc.ie 